\title{
INTRODUCTION Managing, managerial control and
managerial identity in the
post-bureaucratic world
}

\author{
Steve McKenna \\ York University, Toronto, Canada \\ Lucia Garcia-Lorenzo \\ London School of Economics, London, UK, and \\ Todd Bridgman \\ Victoria University, Wellington, New Zealand
}

\begin{abstract}
Purpose - The purpose of this paper is to provide an overview of the issues involved in managerial control and managerial identity in relation to the idea of a post-bureaucratic organization. In addition it introduces the papers in this special issue.

Design/methodology/approach - The paper identifies the increasing complexity of issues of managerial control and managerial identity that arise from the idea of a post-bureaucratic organization and post-bureaucratic working practices, such as flex-work and project management.

Findings - The paper suggests that the form and nature of managerial control and managerial identity are constantly evolving and in a state of flux as a consequence of processes of (de)bureaucratization and (re)bureaucratization.

Originality/value - The paper raises important questions about the nature of management in post-bureaucratic work environments and challenges the behaviourist competencies approach to developing managers.

Keywords Managerialism, Control, Competences

Paper type General review

What is it to "be" in the modern organization? Is it possible to "be" anything or are we destined, as individuals in organizations, to remain constantly "becoming" and thus without permanence, stability, belonging, a common history or coherent narrative? This special issue explores the connectivity between "being and becoming" as it operates at the interface of the relationship between the individual and the organization. In particular we are interested in developing a deeper understanding of what it is to "be" a manager in the modern organization.

This tension between being and becoming in organizations is especially clear in emergent work environments, where the social bond among organizational members is less bureaucratic and more informational. Connectivity among organizational members is developed on a project-by-project basis and the establishment of standards and protocols that are temporary. This way of relating is emerging alongside and sometimes displacing the idea of the organization as a community. A community entails stability and belonging, involving proximity and a common history
\end{abstract}


and narrative developed by the collective. What is it to "be" within this community is grounded; when we see others, in part, we see ourselves.

The discourse of "becoming" on the other hand emphasizes networks, connections, moments, temporariness within which all arrangements are fluid, cursory and superficial. Relationships change from being based on common history and membership and turn to become primarily an exchange of data or "catching up" through processes of integration and disintegration, through virtual and fleeting meetings and acquaintance.

Each of the papers in this special issue deals in some way, with issues of managerial control and managerial identity in a post-bureaucratic world. After introducing these concepts, we then provide a brief overview of the papers.

\section{New forms of bureaucracy and managerial control}

Central to this special issue is the idea that the context of work, especially in Western developed nations, is undergoing a shift away from a traditional, bureaucratic form. Bureaucracy has been the dominant form of organization for more than a century but overtime has acquired a reputation for its association with inefficiency and "red-tape". It is held that the bureaucratic obsession with rule following saps enthusiasm from employees, resulting in organizations which provide poor customer service and are resistant to innovation and change which are assumed to be critical for survival in an increasingly turbulent world (Walker and Brewer, 2009). Furthermore, bureaucracies are considered effective in situations where large numbers of standardized operations are needed but it is argued that these conditions are increasingly rare in today's business world, with even classic bureaucracies such as universities being forced to become more flexible to adapt to changing market conditions (Bolin and Harenstam, 2008). In recognition of these changing conditions, Hecksher (1994) devised a list of ideal characteristics for "post-bureaucracies" which stand in contrast to Max Weber's "ideal bureaucracy". In a post-bureaucratic world, rules are replaced with consensus and dialogue based on personal influence, responsibilities are assigned on merit rather than hierarchy, people are treated as individuals rather than impersonally and the boundaries of the organization are opened.

The concept of "post bureaucracy" is a highly contested term. Ritzer (1996) argues the world is becoming increasingly bureaucratic and for him there is no escape, with bureaucracy spreading first from the manufacturing industry to the service industry, and then to all areas of life. Harris and Höpfl (2006, p. 5) note that:

while there can be little doubt that real and significant changes are underway, it has become apparent that there is no necessary trajectory of historic decline in the bureaucratic form.

They argue that there is not a post-bureaucratic era, but adaptations of bureaucracy. This point is made forcefully by McSweeney (2006) who notes that bureaucratic forms of organization remain persistent and vigorous. Organizations are becoming more hybridized in their form and Josserand et al. (2006, p. 55) argue that:

The refurbished bureaucracy is an original combination of old types in a dynamic perceived as new, leaving a management whose identity was formed in the old ways of doing and being disconcerted as to how to implement changes in their identity that are demanded.

They further note that hybrid forms of organization combine old "rationalization mechanisms with new principles of networks and democracy" (Josserand et al, 2006, p. 55). 
As Kallinikos (2004) suggests the traditional bounded and hierarchical organization is not simply an organizational arrangement but it is also a central institution of modernity. It is closely associated with the key modern values of universality, impersonal treatment and accountability. Further research is required to fully appreciate the current process of hybridization in organizations and its impact on organizational practices such as management.

Hodgson (2004), for example, identified as (re)bureaucratization that which represents new forms of control of employees and the way work is done in organizations. The nature of hybrid organizations and the work that they do requires new mechanisms to manage and undertake short-term assignments and work more generally, such as project management and flexible work practices. In this sense issues of time and space in relation to work become more complex and ambiguous. For example, work may be more project and event driven, and hours of work and the space/location where work is done become more boundaryless. In sum, the complex process of managing cannot be understood by applying approaches that were effective for mechanical organizations, and assembly-line types of technologies and processes.

Putting to one side the debate about whether a shift from a bureaucratic to a post-bureaucratic organization form is occurring, there is also contestation of the binary in which bureaucracy is "bad" and post-bureaucracy is "good" (Grey, 2007). Advocates of post-bureaucracy claim it is an organizational form that liberates employees from the restrictions of bureaucracy (Jamali et al., 2006). Critics, however, note that post-bureaucracy can be a stressful experience for employees, since it weakens job security, intensifies time pressures and places greater responsibility on employees to manage their work lives and careers (Siebers, 2009; McSweeney, 2006). Central to this debate about the desirability of any movement beyond bureaucracy is the issue of control. Indeed, management in a post-bureaucratic world has been characterized as a shift from the "bad old days" of control to a new environment of empowerment and high trust relationships between employees and their managers (Walton, 1985a, b). Implicit in these notions is that managerial control is no longer necessary, because employees can become "self-managing", to the extent that they can be trusted to pursue the goals of the organization with a minimum of direct supervision from managers. While this sounds intuitively appealing, is management without control really possible? Is it possible to "get things done through other people" (as management is commonly defined) purely through developing committed employees?

It is difficult to sustain the argument that control is no longer important in contemporary organizations. While we might accept that post-bureaucracy is based on trust and empowerment, this creates new fears about the loss of managerial control. The fear that employees will pursue goals that are not in the long-term interests of the organization, or that they will work inefficiently or ineffectively, has prompted an interest in forms of control other than formal rules (Barker, 1999; Sewell and Wilkinson, 1992). These normative forms of control received increasing attention from the 1980s onwards with the study or organizational (or corporate) culture. The "culture revolution" reassured managers that if employees internalized the key values of the organization desired by top management (customer service, quality, etc.) then, in essence, they could be trusted to work with a minimum of direct oversight. Management gurus such as Waterman and Peters (2004) went in search of "excellent organizations" to uncover the secrets of organizational culture. 
Closely associated with the concept of culture is that of identity, with both emerging through a process of social interaction, or construction, which cannot be attributed to externally determined categories (Deetz, 1994). Identities are liable to be reformulated as a result of different adaptations, interventions and interpretations by others and therefore are unlikely to be stable (Alvesson and Wilmott, 2002). As organizations harbour greater diversity and reach across larger geographical areas than before the concept of identity becomes stretched to a breaking point. Identity maintenance has therefore become an ongoing worry for managers and the organizations in which they work (Hatch and Schultz, 2004).

Contributions to the literature on identity have come from psychology, social psychology and sociology and have studied the topic from the level of the individual, group and society. For Albert and Whetten (1985) organizational identity refers to those features of the organization that members perceive as central, enduring and distinctive. This can be elicited by asking questions such as "Who are we as an organization?" or "Who do we want to be?" In the Albert and Whetten (1985) formulation, organizational identity is similar to the concept of culture, being a set of basic assumptions shared by members of an organization that defines an organization's distinctiveness. The second notable feature of their definition of organizational identity is the primacy given to cognition, or the perceptions and beliefs of organizational members. Identity is assumed to be the product of cognitive processes and shared understandings, but there is little attention paid to behaviour. A third feature of the Albert and Whetten (1985) concept of organizational identity is the lack of attention given to issues of power. The focus on individual perceptions and beliefs leaves important questions unanswered. Do the perceptions of some members of the organization count more than others? What interests are served by the promulgation of particular organizational identities?

Discourse-based approaches have sought to address this limitation by considering how individual and collective identities are shaped by broader discursive phenomena. Individuals and groups are assumed to have some ability to construct their own reality, though this is always shaped or mediated by the available discursive resources (Humphreys and Brown, 2002). For example, drawing on a narrative approach to organizations, Humphreys and Brown (2002) investigate the efforts of senior managers in a UK institute of higher education to author a hegemonic organizational identity narrative as part of their (ultimately unsuccessful) quest for university status. This involves an analysis of "the often subtle web of power relationships within which people author their self-narratives" (Humphreys and Brown, 2002, p. 423).

Karreman and Alvesson (2004) note the shift away from understanding organizations in material and substantive ways towards constructing them in the imaginary realm. This is especially pertinent in organizations where it is difficult and even counterproductive for managers to deploy traditional, bureaucratic forms of control. In work situations characterized by high levels of autonomy, such as academic work, bureaucratic, or substantive control, is supplemented by forms of cultural-ideological, or normative control. In their study of knowledge intensive firms, Karreman and Alvesson (2004) explore two layers of control. The technocratic layer includes structural elements such as hierarchies, career paths and work methodologies and attempts to control behaviour, while the socio-ideological layer concerns identity and identification and attempts to control beliefs. There is interaction 
between the layers, with social identities providing guidelines for action, making them of interest to managers as a form of control.

\section{New forms of management}

As can be seen from the previous discussion, the changing nature of bureaucracy under certain conditions raises issues for managerial control and managerial identity. But what of management itself? Management is a controversial concept about which there is much disagreement (Thomas, 1993). The way the "problem" of management is framed contributes to its understanding, definition and practice. Of course, managers are not simply passive in this process as they actively seek information and work in the construction of their own practice and identity.

Conventional approaches to organizing have sought to explain the social experience of management in a rational way, by isolating and classifying the putative skills involved in management and how they might be developed within managers. As well as raising issues of managerial control this special issue seeks also to understand management, not as a fixed state, but as an ongoing process of becoming a manager. In addition, issues and questions of managerial identity that arise through this process of being and becoming a manager are highlighted.

A conventional focus of attention with respect to management and managing has been the development of measurable competences. Much continues to be written on the importance of the development of measurable competencies in the production of effective managers (Journal of Management Development, Vol. 27 No. 1). The emphasis in this line of inquiry is on a rationalist and objectivist approach, aiming to identify measurable and developable managerial competencies that will lead to "sustained improvements in the sets of desirable behaviour that lead to outstanding performance". This work has been subjected to criticism, primarily from researchers operating within different paradigms seeking to engage with the experience of managing and specifically being and becoming a manager and managerial identity through different lenses (Alvesson and Wilmott, 2002).

The idea of competencies in the conventional literature is premised on the belief that if competencies and associated desirable behaviours can be discovered, links to performance can be identified. The most desirable competencies and behaviours can then be isolated and developed in all managers as they have purportedly been shown to cause outstanding performance. The process of managerial identity and the associated processes of being and becoming a manager are, in this approach, reduced to a measurable set of behavioural competencies. Competency frameworks, then, enable the development of managerial behaviour in line with a framework that forms a technology of control over managers, which in part will shape their managerial identity (Alvesson and Wilmott, 2002).

This approach to understanding management privileges the discovery, measurement and development of abstract competencies at the expense of the experience of managing. Being and becoming a manager as a phenomenological process and the relationship of this to managerial identity is essentially ignored. Within the competency approach what it takes to become a manager is reduced to sets of identifiable and measurable competencies that reflect knowledge, skills and value, e.g. safety focus, coaching ability, flexibility, team player. Such competencies become a set of skills to learn and behaviours to master. If what and who has to be managed 
changes, a reconfiguration of the skill set and appropriate training and development will ensure that relevant behavioural and competency mastery will continue. Changes that might therefore occur in organizational configurations, in organizing and work arrangements can be managed effectively if managers have competence and competencies that they apply in appropriate ways.

Such a view of management ignores many things about the nature and experience of managing in new organizational forms. First, it misses the point that managers are sentient beings. While there is some recognition that managers can think about managing in the context of some competency ideal, essentially the competency approach treats managers as malleable functionaries. Once "science" has determined what behaviours are best for outstanding performance managers are simply to be trained. Second, the competency approach largely ignores the organizational and social contexts within which managers manage. In particular here is the political dynamic of organizations that largely governs the way of managing, and the nature and purpose of management in wider society. Related to this is the idea that competencies enable both control of managers and enhance their capability to control others. In short, managers are likely to be pulled and pushed in many different directions as to how they have to "be" that imply the "science" of competencies is limited in its ability to understand the processes of identity construction and (re)construction with which managers struggle. Indeed, competency studies dehumanize not only the process of being and becoming a manager, but also the person who is manager. Managers are written about as if they are mere repositories for knowledge, skills and "things" of apparent value.

\section{Overview of the special issue}

The form and nature of managerial control and managerial identity is constantly evolving and in a state of flux as a consequence of processes of (de)bureaucratization and (re)bureaucratization. Such developments inevitably raise issues concerning the management of employees, the nature of managing, and the nature of managerial identity itself. Associated questions involve relations of trust in these changing environments; the personal and professional selves and identities of managers; and how gender issues in management are influenced by hybridized organizational forms and new ways of organizing. Furthermore there are important questions about the development of managers for "post-bureaucracy" (Hendry, 2006). Given that changes in the organization of work seem to be occurring, as both (de)bureaucratization and (re)bureaucratization, what are the implications for management development?

In this special issue these questions are addressed, not in order to find "solutions" but to promote debate about managerial identity and what it is to be a manager in a contemporary organization. While admitting that managers need and will continue to act and intervene in the practical world, we hesitate to provide them with (the illusion of) easy solutions and deceivingly deployable agendas and recipes. Our contribution consists in enriching the premises of managerial choice and action with stories, interpretations and useful cases of being a manager in the twenty-first century organization.

In this regard the special issue begins with two empirical papers that relate to post-bureaucratic working arrangements. Richardson explores what it means to be a manager in the context of working from home and investigates some of the issues in managing flexworkers. While her paper highlights some very specific practical implications for developing managers of flexworkers, her analysis of interviews with 
twenty-seven managers from the Canadian subsidiary of a high-tech MNC, raises important issues of trust and the ability of managers to "let-go" of control over their staff. Given that control over employees goes to the very heart of management, this struggle is central to a re-orientation of the managerial role in flexible working arrangements.

Tietze and Musson are concerned also with managers working from home. The focus of their paper is the identity work that managers undertake in order to "(re)establish a sufficiently stable sense of self". Using case studies of three managers, the authors investigate the experiences of managers and their co-habitants and found that working from home had implications for their occupational as well as personal identities. How the managers dealt with these identity struggles led to different outcomes for each participant as they sought to find their own way to a resolution.

Project work and project management is also considered an exemplar of a post-bureaucratic working arrangement. Work and organizing is viewed as a sequence of events tied to processes that contribute to the completion of a project rather as an integral aspect of a bureaucratic structure. Paton et al. explore the tensions inherent in the process involved in becoming a project manager. They highlight the identity issues relevant to enacting the role of project manager many of who are often moving from more established professional disciplines such as engineering to become a project manager.

Andersson's paper reports findings from research carried out with five managers over a two year period in Swedish-based organizations. The focus of his paper is to explore how participation in a personal development programme impacted the professional identity of the managers. He discovers that such programmes, rather than "developing managers", may serve to help managers realize their alienation from their managerial identity and role in bureaucratic organizations. As a consequence they increasingly dis-identify with their organization to the point where they may leave to achieve greater personal authenticity (Costas and Fleming, 2009).

The issue of authenticity, identity and managerial behaviour is a feature of the paper by Budworth and Mann. They consider the relationship between modesty and access to leadership positions for women, arguing that women have to develop appropriate levels of self-promotion in order to realize accession to leadership. The requirement to be "different" in order to achieve organizational success raises important questions about gender socialization and behaviour. It will simultaneously raise questions that pertain to authenticity and identity as women assume new behaviours to achieve career success.

Overall this special issue is concerned with recognizing the complexity of managerial control, managerial identity and managing in the contemporary organization. Rather than claiming that being and becoming a manager concerns the "science" of behaviours, we propose a more nuanced and constructivist approach, whereby managers make sense of who they are and what they do within the contexts in which they operate. We hope that the papers in this special issue contribute to this debate.

\section{References}

Albert, S. and Whetten, D. (1985), "Organizational identity", Research in Organizational Behavior, Vol. 7, pp. 263-95.

Alvesson, M. and Wilmott, H. (2002), "Identity regulation as organizational control producing the appropriate individual", Journal of Management Studies, Vol. 39 No. 5, pp. 619-44. 
Barker, J. (1999), "Tightening the iron cage: concertive control in self-managing teams", Administrative Science Quarterly, Vol. 38, pp. 408-37.

Bolin, M. and Harenstam, A. (2008), "An empirical study of bureaucratic and post-bureaucratic characteristics in 90 workplaces", Economic and Industrial Democracy, Vol. 29 No. 4, pp. 541-64.

Costas, J. and Fleming, P. (2009), "Beyond dis-identification: a discursive approach to self-alienation in contemporary organizations", Human Relations, Vol. 62 No. 3, pp. 353-78.

Deetz, S. (1994), "The future of the discipline: the challenges, the research, and the social contribution", in Deetz, S. (Ed.), Communication Yearbook 17, Sage, Thousand Oaks, CA.

Grey, C. (2007), "Bureaucracy and post-bureaucracy", in Knights, D. and Willmott, H. (Eds), Introducing Organizational Behaviour and Management, Thomson, London.

Harris, M. and Höpfl, H. (2006), "Introduction", Journal of Organizational Change Management, Vol. 19 No. 1, pp. 5-7.

Hatch, M. and Schultz, M. (2004), Organizational Identity, Oxford University Press, Oxford.

Hecksher, C. (1994), "Defining the post-bureaucratic type", in Hecksher, C. and Donnellon, A. (Eds), The Post-bureaucratic Organization: New Perspectives on Organizational Change, Sage, Thousand Oaks, CA.

Hendry, J. (2006), "Educating managers for post-bureaucracy: the role of the humanities", Management Learning, Vol. 37 No. 3, pp. 267-81.

Hodgson, D.E. (2004), "Project work: the legacy of bureaucratic control in the post-bureaucratic organization", Organization, Vol. 11 No. 1, pp. 81-100.

Humphreys, M. and Brown, A.D. (2002), "Narratives of organizational identity and identification: a case study of hegemony and resistance", Organization Studies, Vol. 23 No. 3, pp. 421-47.

Jamali, D., Khoury, D. and Sahyoun, S. (2006), "From bureaucratic organizations to learning organizations: an evolutionary road-map", The Learning Organization, Vol. 13 No. 4, pp. 337-52.

Josserand, E., Teo, S. and Clegg, S. (2006), "From bureaucratic to post-bureaucratic: the difficulties of transition", Journal of Organizational Change Management, Vol. 19 No. 1, pp. 54-64.

Kallinikos, J. (2004), "The social foundations of the bureaucratic order", Organization, Vol. 11 No. 1, pp. 13-36.

Karreman, D. and Alvesson, M. (2004), "Cages in tandem: management control, social identity, and identification in a knowledge-intensive firm", Organization, Vol. 11 No. 1, pp. 149-75.

McSweeney, B. (2006), “Are we living in a post-bureaucratic epoch?”, Journal of Organizational Change Management, Vol. 19 No. 1, pp. 22-37.

Peters, T.J. and Waterman, R.H. (2004), In Search of Excellence, HarperCollins, New York, NY.

Ritzer, G. (1996), The McDonaldization of Society: An Investigation into the Changing Character of Contemporary Social Life, Pine Forge Press, Thousand Oaks, CA.

Sewell, G. and Wilkinson, B. (1992), "Someone to watch over me: surveillance, discipline and just-in-time labour process", Sociology, Vol. 26 No. 12, pp. 271-89.

Siebers, H. (2009), "(Post)bureaucratic organizational practices and the production of racioethnic inequality at work", Journal of Management and Organization, Vol. 15 No. 1, pp. 1-10.

Thomas, A.B. (1993), Controversies in Management, Routledge, London.

Walker, R.M. and Brewer, G.A. (2009), "Can management strategy minimize the impact of red tape on organizational performance?", Administration and Society, Vol. 41 No. 4, pp. 423-48. 
Walton, R.E. (1985a), "Toward a strategy of eliciting employee commitment based on policies of mutuality", in Walton, R.E. and Lawrence, P.R. (Eds), Human Resource Management: Trends and Challenges, Harvard Business School Press, Boston, MA.

Walton, R. (1985b), "From control to commitment in the workplace", Harvard Business Review, March-April, pp. 77-84.

\title{
Further reading
}

du Gay, P. (2005), The Values of Bureaucracy, Oxford University Press, Oxford.

\begin{abstract}
About the Guest Editors
Over the last 20 years, Steve McKenna has combined an academic with an industry career that has enabled him to work in Europe, North America and Asia. Over the years, he has developed a number of core research interests in the area of internationally mobile skilled workers and independent expatriates. Additionally, he has interests in the global human resource management activities of companies from rapidly developing economies and alternative and critical approaches to human resource management. He has also published widely in the area of management development and has been critical of competency modelling and argues for new approaches to management and leadership development that engage the context within which a manager works. He is currently engaged in writing up work on managerial narratives and organizational learning and also a study of Canadian engineers in the UAE and Australia. He also has an interest in professionalization and particularly the professionalization of HRM. He is primarily a qualitative researcher using creative interviewing, narrative approaches, ethnography, and case study methodologies to explore and interpret findings in his areas of interest. He received his $\mathrm{PhD}$ from the University of Warwick in the UK and has consulted to organizations and governments around the world. Steve McKenna is the corresponding author and can be contacted at: smckenna@yorku.ca

Lucia Garcia-Lorenzo trained as a social psychologist in northern Spain before moving to London to conduct research towards a $\mathrm{PhD}$ at the London School of Economics on cultural change in organisations, after major transitions. Since then, she has taken part in a number of international research projects focused on change processes in organisations in different contexts. Currently she is lecturing at the London School of Economics, where she directs a postgraduate program in organisational and social psychology and is involved in research looking at networking, knowledge development, and collaboration among NGOs in the UK as well as among small- and medium-sized enterprises in Europe.

Todd Bridgman is Senior Lecturer in Organisational Behaviour at Victoria University of Wellington, Wellington, New Zealand.
\end{abstract}

